\title{
Preparation of Mission Grass Flower-Based Activated Carbon Monolith Electrode for Supercapacitor Application
}

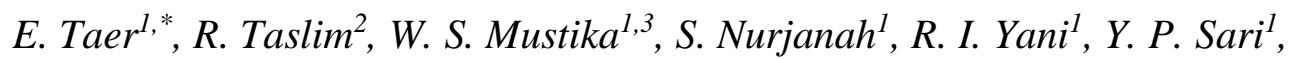

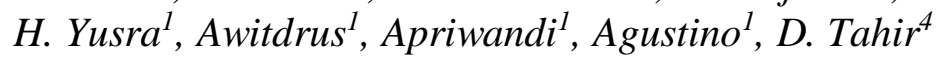 \\ ${ }^{1}$ Department of Physics, University of Riau, 28293 Simpang Baru, Riau, Indonesia. \\ ${ }^{2}$ Department of Industrial Engineering, Islamic State University of Sultan Syarif Kasim, \\ 28293 Simpang Baru, Riau, Indonesia. \\ ${ }^{3}$ Department of Physics, Institute Technology of Bandung, Bandung, West Java, Indonesia \\ ${ }^{4}$ Department of Physics, Hasanudin University, Makassar, South Sulawesi, Indonesia \\ *E-mail: eman.taer@yahoo.com
}

doi: $10.20964 / 2019.08 .82$

Received: 6 April 2019 / Accepted: 2 June 2019 / Published: 30 June 2019

\begin{abstract}
The preparation and characterization of an activated carbon monolith for supercapacitor application created from mission grass flowers was performed. The benefits of carbon electrode monolith production from mission grass flowers include the low cost of the raw material and smooth structures that can bind without the use of an adhesive. Carbon electrode preparations were evaluated with respect to several aspects: chemical activating agent, carbonization temperature, and physical activation temperature and particle size. These aspects represent several main aspects in the production of carbon electrodes. The primary characterization required to determine carbon electrode properties is based on the specific surface area and capacitance. Our characterization found that a carbon electrode monolith manufactured from mission grass flowers had a maximum surface area of $950 \mathrm{~m}^{2} \mathrm{~g}^{-1}$ and a maximum specific capacitance of $120 \mathrm{~F} \mathrm{~g} \mathrm{~g}^{-1}$. In addition, the crystallinity and morphology of the monolith's surface properties were tested and analysed.
\end{abstract}

Keywords: Mission grass; carbon electrode; specific capacitance; supercapacitor

\section{FULL TEXT}

(C) 2019 The Authors. Published by ESG (www.electrochemsci.org). This article is an open access article distributed under the terms and conditions of the Creative Commons Attribution license (http://creativecommons.org/licenses/by/4.0/). 